\title{
AfricArXiv
}

\section{Democratizing Higher Education in Zambia \\ Through Open Access Data}

Jane Chinkusu ${ }^{1}$, Filipo Zulu ${ }^{2}$, Daryl Naylor ${ }^{3}$, Joy Owango ${ }^{4}$

${ }^{1}$ Ministry of Higher Education (Zambia), ${ }^{2}$ National Science and Technology Council (Zambia),

${ }^{3}$ Digital Science, ${ }^{4}$ TCC Africa

Published on: Mar 11, 2021

DOI: $10.21428 / 3 b 2160 c d .88 f d 0530$

License: Creative Commons Attribution 4.0 International License (CC-BY 4.0). 
Democratizing Higher Education in Zambia Through Open Access Data

Hosted By

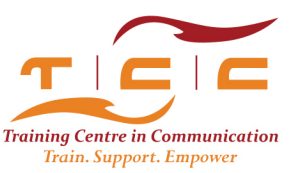

Guest Speakers

Daryl Naylor

Sales Director, EMEA

Digital Science (UK)

Mrs. Jane Chinkusu

The Director, Department of Science and Technology (DST), Ministry of

Higher Education(Zambia)

Filipo Zulu

Acting Executive Secretary/CEO,

National Science and

Technology Council (Zambia)
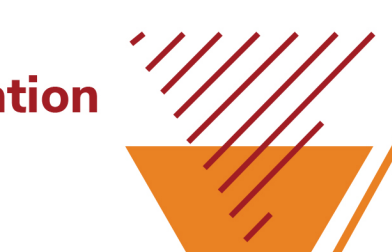
democratizing higher education in Zambia

What does the future hold for the Zambia academic community with open access?

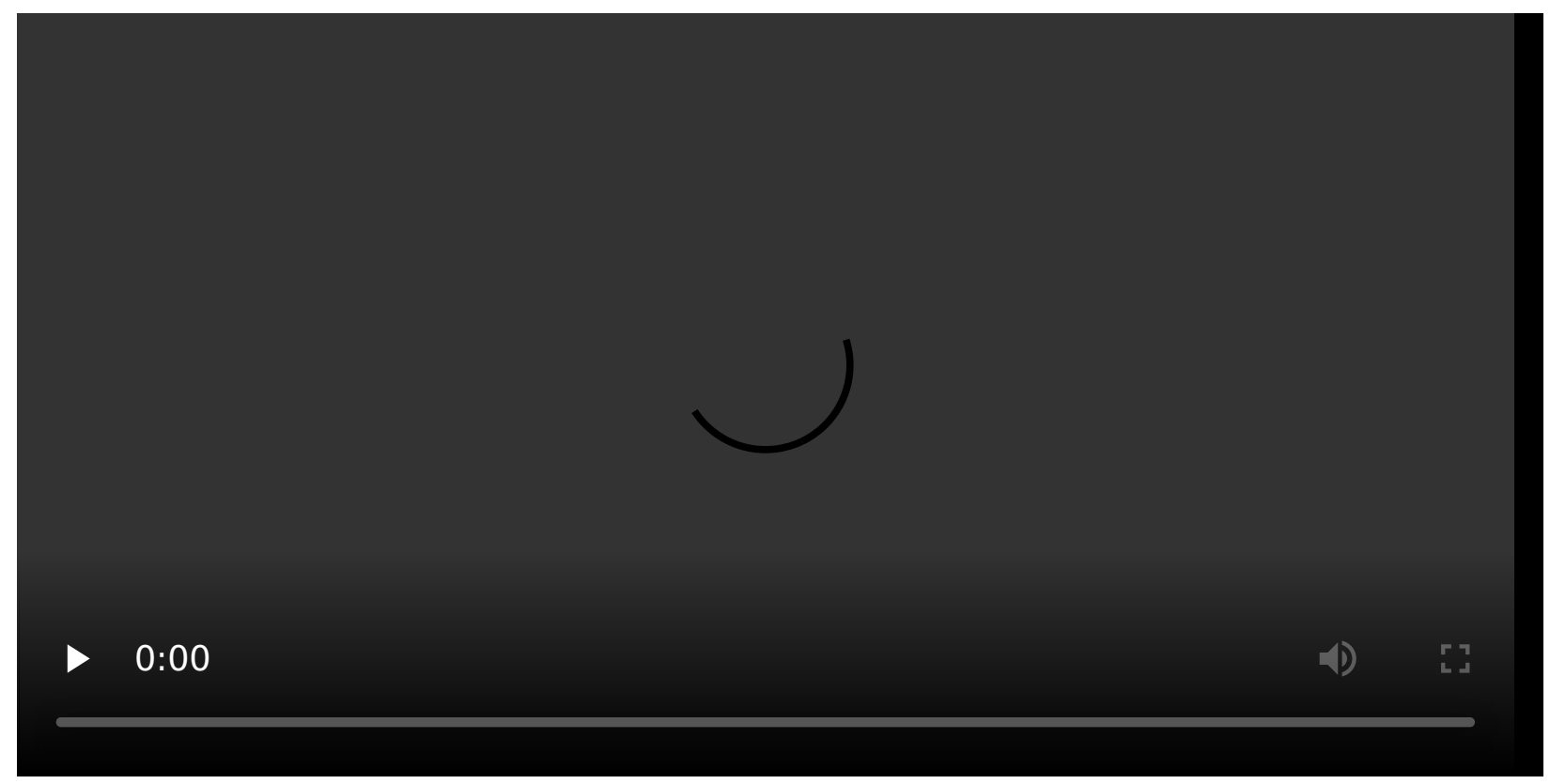

